\title{
Psychological Wellbeing of the Minor in Conflict with the Law
}

\author{
Ardita Prendi \\ Ph.D.Candidate, University of Tirana, Faculty of Social Science \\ e-mail:arditaprendi@yahoo.com
}

\section{Doi:10.5901/mjss.2014.v5n4p488}

\section{Abstract}

There is little doubt that being incarcerated is a stressful experience for many juvenile delinquents. Early researchers suggested that imprisonment had negative psychological and physical effects on its inmates, leading to psychological deterioration. This article aims to provide an overview of the coping strategies, adjustment and well-being in the prison environment. The study is qualitative and was conducted at the premises of the Institute of Minors Kavaja. The group of minors investigated is of age 14-18 years, this age coinciding with the age when one is held responsible of criminal activity. The psychosocial analysis focuses on the psychological reactions of these minors as a result of frustration or inadequacy and lack of communication, low self-esteem, the closure in themselves, the expression of aggression, fear of the unknown, anxiety and social withdrawal, being sensitive to the reaction of others, etc., these elements can determine the course of the well-being of minors in isolation environments The results demonstrate that there is a complex relationship between the coping strategies, adjustment (adaption) and well-being of minor and that institutional opportunities and changes can be beneficial. In the end, this article gives some recommendations how to get better some elements that influenced in well-being, across efficient involvement of educational staff, the police and other social agents who cooperate with the institution or created specific programs for this target.

Keywords: psychological well-being, minor in conflict with law, adaption, copping strategies.

\section{Introduction}

\subsection{Prison populations}

Nowadays the involvement of minors in criminal activities has become a problem. Official statistics in Albania and in the world show that the number of juveniles who commit serious crimes: murder, theft, and even engage in drug trafficking has increased.Involvement of juveniles and young people in criminal activities have turned into a distress for Albanians, especially in the last decade. Juvenile delinquency appeared and quickly became a serious issue at the beginning of the 90 's. Involvement of juveniles in criminal activity is associated with individual and external factors which create an environment for criminal behavior. Juveniles in conflict with the law are 2 to 3 times more prone to get involved in serious, violent and chronic offences than other individuals who get involved in crime at a later stage in their life. The age of the researched group of minors ranges from 14 to 18 years old, this age coinciding with the age of criminal accountability. According to records from Ministry of Justice in 2004 there were 313, in 2008 there were 356 and in 2010 there were 594 juvenile delinquency. Higher rate of juvenile delinquency isconcentrated primarily in main urban centres like Tirana, Korça, Durrës, Elbasan, Gjirokastër,Vlorë and Berat

Table 1. Sentenced offenders in Albania (2004-2010)

\begin{tabular}{|l|c|c|c|c|c|c|c|}
\hline \multicolumn{1}{|c|}{ (Juvenile Delinquency) } & $\begin{array}{c}\text { (Year) } \\
2004\end{array}$ & $\begin{array}{c}\text { (Year) } \\
2005\end{array}$ & $\begin{array}{c}\text { (Year) } \\
2006\end{array}$ & $\begin{array}{c}\text { (Year) } \\
2007\end{array}$ & $\begin{array}{c}\text { (Year) } \\
2008\end{array}$ & $\begin{array}{c}\text { (Year) } \\
2009\end{array}$ & $\begin{array}{c}\text { (Year) } \\
2010\end{array}$ \\
\hline (Criminal offenses) & 313 & 258 & 238 & 198 & 356 & 362 & 594 \\
\hline (Contraventions) & 7 & 31 & 30 & 13 & 51 & 49 & 62 \\
\hline Total & 320 & 289 & 268 & 211 & 407 & 411 & 656 \\
\hline
\end{tabular}

By comparing the above numbers, one can see that juvenile criminality followed a steady trend from 2004 to 2010 . It has increased proportionally with the overall criminality and is mostly seen in the main urban centres of the country. 


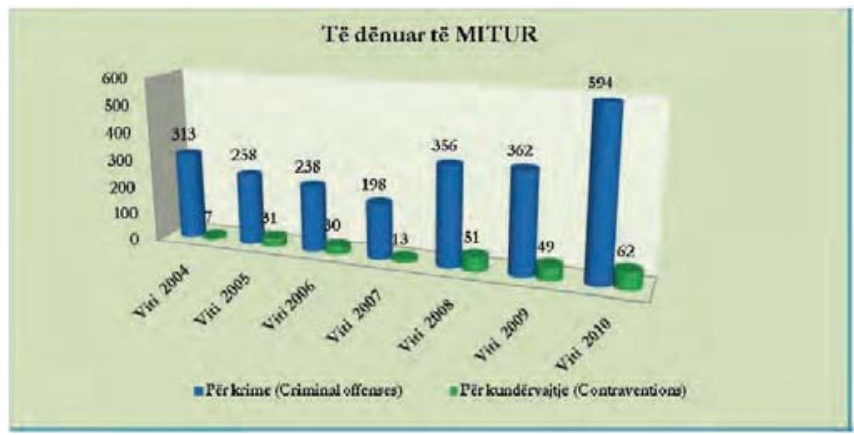

Figure: Vjetari statistikor 2010

\subsection{Pains of imprisonment}

Many juveniles have problems adjusting to life in correctional institutions because their loose and unstructured behavior patterns on the outside were suddenly brought to an end by the process of arrest and incarceration (Zamble and Porporino, 1988). Successful adaption to prison may depend on a number of factors, including the prisoner's background, individual characteristics, situational factors and the environment (Power, McElroy \& Swanson, 1997). Adjustment to prison life has long been conceptualised as the degree to which inmates can endure the 'pains of imprisonment' (Sykes, 1958), which have been defined as deprivations of autonomy, liberty, security, relationships and goods and services. The loss of liberty and autonomy are probably the most immediately obvious pains of being imprisoned, with prisoners' freedom of movement within the establishment also often greatly restricted by the prison regime. Studies have indicated that perceived lack of autonomy is associated with psychological distress in prisoners (Goodstein, MacKenzie \& Shotland, 1984; Wright, 1993). Similarly, a greater deprivation in contact with friends or family outside of prison has been shown to be associated with poorer psychological health in prisons (Liebling, 1992; Wooldredge, 1999).

The importation model (Irwin \& Cressey, 1962) focuses on the importance of pre-existing individual characteristics and attitudes of inmates that are 'imported' with them to prison, including demographic factors, prior experience in prison and family life. Importation theory suggests that these characteristics are critical components in determining how well prisoners adapt emotionally to life behind bars.

Recent research suggests that the interaction between imported characteristics and deprivations of prison is probably the best way to conceptualise how well prisoners will cope with imprisonment (Davidson-Arad, 2005; Gover \& MacKenzie, 2003)

\subsection{Psychological impact of imprisonment}

There are a number of difficulties in exploring the psychological impact of imprisonment upon individuals. According to Wooldredge (1999) psychological well being is conceptualized as "reflecting inmate perceptions of insecurity, stress, depression, anger, low self esteem and loneliness felt during incarceration". Particular aspects of the prison environment may lessen some of the negative psychological effects of incarceration, such as depression and alienation, but they depend on the unique need of the inmates (Toch, 1977). The factors that have a beneficial impact on psychological wellbeing while incarcerated include social integration (Lindquist, 2000), not

being victimized (Leddy \& O'Connell, 2002), and frequent visitation (Woolredge, 1999). Boxer, Middlemass and Delorenzo (2009) found that both direct and indirect experiences of violence in prison were significantly associated with emotional distress. There are many factors which can contribute to negative reactions to imprisonment. Hayes and Blaauw (1997) suggest that certain features of the prison setting can negatively affect coping and adjustment to imprisonment. These include: fear of the unknown, distrust of authoritarian environment, lack of apparent control over the future, isolation from family, the shame of imprisonment and the dehumanising effects of imprisonment. 


\subsection{Coping in youth prison}

There are limited studies directly exploring how prisoners cope with the 'pains of imprisonment'. One aspect that has been found to impact upon how individuals respond to stressful events is the support available to them (Listwan, Colvin, Hanley \& Flannery, 2010). Studies within prisons have demonstrated that social support helps to diminish the impact of violence and other prison hardships upon prisoners' psychological wellbeing (Biggam \& Power, 1997; Hochstetler, DeLisi \& Pratt, 2010; Liebling, 1992; Wooldredge, 1999). Firstly, the minors must adapt practically to his new environment; secondly he must adapt socially to be able to interact with staff and inmates; and finally, he must adapt psychologically, which involves both problem- and emotion-based coping.

\subsection{The present article}

This article aims to provide an overview of the coping strategies, adjustment and well-being in the youth prison environment.

There have been identified a number of specific objectives:

1. To determine if coping strategies affect the adaptation, adjustment and well being of inmates.

2. To determine if institutional opportunities or changes can improve inmate adjustment and coping

The above, and a number of other secondary questions, are essential in the struggle to understand what happens to the development process (social, cognitive, emotional) of the minors in isolation.

1. Which is the emotional situation of the minors in conflict with the law, as they have committed delinquent behavior?

a. How do they face the situation they are in to?

b. The experiencing traumas?

2. What did they find in jail?

a. How will you they cope with the new life?

b. Will they fit with the new lifestyle that awaits them?

c. Will they be part of social groups, if there is any?

d. What would be the relationship, socialization, and communication with new people, objects, rules, and the isolation in general, etc?)

\section{Metodology}

\subsection{Participants}

The population is composed of a specific group of 36 , as of IMK. The number of minors is changing due to the dynamic process, short prison sentences, frequent releases and new entries into custody. This group is selected:

- Because the phenomenon is visible and in the best case is preventable, as new individuals have not entered into the path of true crime yet.

- There are no proper studies in forensic psychology in Albania and the number of minors incriminated recent years has been growing. (Vjetari-statistikor, 2010)

- The need for immediate intervention, as a minor, regardless of the type of delinquent act, when enters detention facilities, suffers a kind of psychological shock or transformation, the shock which does not take into account the further development of the individual after he has served the sentence.

\subsection{Procedure}

Participants were interviewed for about one hour (results not reported here) and afterwards filled out a questionnaire. All respondents participated voluntarily, signed an informed consent declaration and were told that their answers would be treated confidentially and processed anonymously and would be accessed only by the researchers. All names on the questionnaires and interview transcripts were deleted and given a code number. In order to protect the privacy of the respondents, researchers had no access to the names. 
To conduct the study, there has been used mixed methodology: the study of literature, documented material (psychosocial files), observation and questionnaires. (Miles, M. B. \& Huberman, M. (1994).)

a. direct and non direct participatory observation, conducted over a time frame of 24 weeks. Juvenile behavior is observed in everyday life, but also in activities such as: work groups, sports, art activities, etc.

b. free conversations with minors are conducted in group work and treatment sessions for conflict resolution through dialogue. Also free discussions were conducted during individual meetings with minors.

c. questionnaires were completed during December 2011-March 2012, which included 36 minor inmates and detainees in IMK. Briefly, Ryff's scales of psychological well-being (PWB) include the following six components of psychological functioning: a positive attitude toward oneself and one's past life (selfacceptance), high quality, satisfying relationships with others (positive relations with others), a sense of selfdetermination, independence, and freedom from norms (autonomy), having life goals and a belief that one's life is meaningful (purpose in life), the ability to manage life and one's surroundings (environmental mastery), and being open to new experiences as well as having continued personal growth (personal growth).

\section{Results and Discussion}

\subsection{The Psychological Effects of Incarceration:}

This article focuses on the broader and more subtle psychological changes that occur in the routine course of adapting to prison life. The term "institutionalization" is used to describe the process by which inmates are shaped and transformed by the institutional environments in which they live.Being in isolation conditions creates psychological effects for minors and with each other as well as in some aspects of their development, as a result of frustration or inadequacy and lack of communication, low self-esteem, the closure in themselves, the expression of aggression, fear of the unknown, anxiety and social withdrawal, being sensitive to the reaction of others, etc., these elements can determine the course of the psychological wellbeing of minors in isolation environments. (Abrahamsen, 1960).

The adaptation to imprisonment is almost always difficult and, at times, creates habits of thinking and acting that can be dysfunctional in periods of post-prison adjustment. Yet, the psychological effects of incarceration vary from individual to individual and are often reversible.

When most people first enter prison, of course, they find that being forced to adapt to an often harsh and rigid institutional routine, deprived of privacy and liberty, and subjected to a diminished, stigmatized status. Persons gradually become more accustomed to the restrictions that institutional life imposes. The various psychological mechanisms that must be employed to adjust (and, in some harsh and dangerous correctional environments, to survive) become increasingly "natural," second nature, and, to a degree, internalized. To be sure, the process of institutionalization can be subtle and difficult to discern as it occurs.

The process of institutionalization is facilitated in cases in which persons enter institutional settings at an early age, before they have formed the ability and expectation to control their own life choices. Because there is less tension between the demands of the institution and the autonomy of a mature adult, institutionalization proceeds more quickly and less problematically with at least some younger inmates. Moreover, younger inmates have little in the way of already developed independent judgment, so they have little if anything to revert to or rely upon if and when the institutional structure is removed. And the longer someone remains in an institution, the greater the likelihood that the process will transform them.

Among other things, the process of institutionalization (or "prisonization") includes some or all of the following psychological adaptations:

\subsection{Hypervigilance}

Research has shown that inmates exhibit higher levels of anxiety and depression than the general population, along with lower levels of self esteem, specifically among certain groups of inmates (Castellano and Soderstrom, 1997). This suggests that programs need to be in place to improve inmates self esteem. Furthermore, the threat or persistent fear of victimisation among inmates that is presented in the prison environment can lead to hypervigilance. Hypervigilance is the "sustained heightened cognitive and affective arousal in the service of scanning the environment for threats" (Boxer et 
al., 2009) and is a key component of anxiety related syndromes.

\subsection{Alienation and psychological distancing}

The alienation and social distancing from others is a defense not only against exploitation but also against the realization that the lack of interpersonal control in the immediate prison environment makes emotional investments in relationships risky and unpredictable.

\subsection{Social withdrawal and isolation.}

Some minors in conflict with law learn to find safety in social invisibility by becoming as inconspicuous and unobtrusively disconnected from others as possible. The self-imposed social withdrawal and isolation may mean that they retreat deeply into themselves, trust virtually no one, and adjust to prison stress by leading isolated lives of quiet desperation.

\subsection{Incorporation of exploitative norms of prison culture.}

In addition to obeying the formal rules of the institution, there are also informal rules and norms that are part of the unwritten but essential institutional and inmate culture and code that, at some level, must be abided. For some prisoners this means defending against the dangerousness and deprivations of the surrounding environment by embracing all of its informal norms, including some of the most exploitative and extreme values of prison life

\subsection{Diminished sense of self-worth and personal value.}

Prisoners typically are denied their basic privacy rights, and lose control over mundane aspects of their existence that most citizens have long taken for granted. They live in small, sometimes extremely cramped and deteriorating spaces (have little or no control over the identify of the person with whom they must share that space (and the intimate contact it requires), often have no choice over when they must get up or go to bed, when or what they may eat, and on and on. Some feel infantalized and that the degraded conditions under which they live serve to repeatedly remind them of their compromised social status and stigmatized social role as prisoners. A diminished sense of self-worth and personal value may result. In extreme cases of institutionalization, the symbolic meaning that can be inferred from this externally imposed substandard treatment and circumstances is internalized; that is, prisoners may come to think of themselves as "the kind of person" who deserves only the degradation and stigma to which they have been subjected while incarcerated.

\subsection{Post-traumatic stress reactions to the pains of imprisonment.}

For some prisoners, incarceration is so stark and psychologically painful that it represents a form of traumatic stress severe enough to produce post-traumatic stress reactions once released. A "risk factors" model helps to explain the complex interplay of traumatic childhood events (like poverty, abusive and neglectful mistreatment, and other forms of victimization) in the social histories of many criminal offenders. As Masten and Garmezy(1985) have noted, the presence of these background risk factors and traumas in childhood increases the probability that one will encounter a whole range of problems later in life, including delinquency and criminality.

Psychological features. Psychological studies of delinquent have focused on determining specific features of personality that lead people to become delinquent. They have shown that many delinquent are emotionally disturbed, have emotional and behavioral disorders.

Antisocial behavior. It is characteristic for juveniles in conflict with the law. They are known for intolerant discussions, limited communication skills and their self-control problems in some situations.

Closing in themselves. Ways of experiencing the judicial process and living in detention, are positive or negative amplifier of further psychological response of the individual (eg, police uniforms, isolation conditions itself forced environment,the presence of a psychologist, etc.). Closing in himself as the kind of reaction in terms of isolation is very familiar. Many were minors cases closed in themselves and did not want to talk.

"Sometimes I do not want to talk to anyone. I would be very comfortable I had noone in the room ... Sometimes I talk to the moon. I feel like it understands and above all it is loyal, does not says to anyone my secrets " 
Pathological Disorders. From conversations with the psychologist and social worker of this institution, we found out that only in rare cases they delt with juvenile with psychopathic disorders. The majority of juveniles have disssocioal characters and are driven by special circumstances for committing delinquent activity for which they serve sentences or are awaiting trial. In terms of isolation and being controlled and monitored minors should repel instincts and this creates a difficult psychological situation to this category, what is demonstrated in their behavior and in their mode of communication. If we speak the language Freudian, repel, not fulfillement of instincts, results in various neuroses, pathological excesses, mistakes in speaking etc.

Superiority / inferiority. The are minors who want to prove superior, to have an impact on sector, that are impetuous, aggressive, who can not manage frustacionin, anger. Everyone wants be in the center of attention, to be "leader", to be heard. In some cases this leads to disputes, fights of moment or resentment. But there are minors that due to specific psycho-affective situations, due to being suspicious towards others, family problems, feel inferior.

\section{Limitations of the Study}

The study was based in the use of three methodological instruments, aiming to collect data as complete and accurate.

First; in direct participating observations, minors feeling observed, not always behaved naturally, but sometimes were limited by manipulating their behavior, which created difficulties in a clear understanding of situation.

Secondly; free conversations may not always be "free." Availability in terms of isolation was limited. Minors were generally inclined to give less information; being suspicious especially with new people they made contact. Generally they had belief that the data obtained from their conversations could be used to cause investigation and inquiry and this made in communication limited and often repulsive

Thirdly, the use of questionnaires not always proved successful. This is not only for the above reasons, but also for fact that completion of questionnaires, created the idea that what they claimed, would be reported somewhere and can be used for other purposes and in some cases they refused to participate in fulfillment of questionnaires.

\section{Conclusions and Recommendations}

The coping strategies are associated with adjustment and the well being of minors but this relationship is perhaps more complex than first thought. Furthermore, institutional opportunities and changes are instrumental in how inmates cope and adjust to the prison environment.It is clear that the minors in conflict with law adjusted and coped with life imprisonment differently depending on the following: their personality, in particular, their dispositional position regarding hope and optimism; their ability to fashion a routine that gives their lives meaning and purpose; their ability to submit to the prison regime yet retain a sense of autonomy and control over their lives; the quality of their family contact; and the opportunities to avail of work and education. What is apparent from this article is that minors learn to live within the limitations of confinement. They settle in, they develop a routine for themselves and learn to live with the pains of imprisonment.

In addition to this, therapeutic groups and others actors are important for minors' adjustment and coping in prison. Furthermore, institutional opportunities and programs are beneficial for minors; therefore more need to be provided in order to make the prison experience as beneficial as possible. As a way of coping with prison life, emotion coping strategies have been shown to be more effective than other strategies (Van Herreveld et al., 2007).

This is particularly important because negative emotions such as disappointment and regret are related to psychological and physical health. Suppressing these negative emotions can also have adverse consequences. This suggests that some sort of program or group work which encourages inmates to share their feelings, rather than suppressing them, could be beneficial.

Creating a sense of trust and cooperation to counter feelings of suspicion and competition that often created in the conditions of isolation. This requires that all actors operating in minor's institution to work in coherence and to be cooperative. The minors in conflict with law must be given opportunities to engage in meaningful activities, to work, to educate while incarcerated. Psychologists can recommend programs which will best match offenders to their needs. These might include substance-abuse treatment programs, development of reading and writing skills, decision-making, anger control, meaningful job training, contact with families, or sex offender treatment. Their minimum goal may be to help inmates cope with the realities of prison life. However, such programs will only be beneficial if inmates enter them voluntarily and take them seriously. 


\section{References}

Abrahamsen, David, 1960. The Psychology of Crime. New York: Columbia Univ. Press.

Bartol, C.R., \& Bartol, A.M. (1994). Psychology and Law: Research and Application (2nd ed.). Pacific

Biggam, F. H., \& Power, K. G. (1997). Social support and psychological distress in a group of incarcerated young offenders. International Journal of Offender Therapy and Comparative Criminology, 41, 213-230.

Castellano, T. C. \& Soderstrom, I. R. (1997) 'Self-Esteem, Depression, and Anxiety

Evidenced by a Prison Inmate Sample: Interrelationships and Consequences for Prison Progamming'. The Prison Journal 77 (3): 259280

Davidson-Arad, B. (2005). Observed violence, abuse, and risk behaviors in juvenile correctional facilities: Comparison of inmate and staff reports. Children and Youth Services Review, 27, 547-559

Goodstein, L., MacKenzie, D. L., \& Shotland, R. L. (1984). Personal control and inmate adjustment to prison. Criminology, 22, 343-369

Gover, A. R., \& MacKenzie, D. L. (2003). Child maltreatment and adjustment to juvenile correctional institutions. Criminal Justice and Behavior, 30, 374-396.

Hayes, L. M. \& Blauuw, E. (1997) 'Prison Suicide: A Special Issue'. Crisis 18 (4): 146- 148

Haney, C. (2001). The psychological impact of incarceration: Implications for post prison adjustment. Retrieved March 10, 2012, from http://aspe.hhs.gov/hsp/prison2home02/ haney.pdf.

Hochstetler, A., DeLisi, M., \& Pratt, T. C. (2010). Social support and feelings of hostility among released inmates. Crime \& Delinquency, $56,588-607$.

Irwin, J., \& Cressey, D. (1962). Thieves, convicts, and the inmate culture. Social Problems, 10, 142-155

Lazarus, R. S., \& Folkman, S. (1984). Stress, appraisal, and coping. New York: Plenum Press.

Leddy, J., \& O'Connell, M. (2002). The prevalence, nature and psychological correlates of bullying in Irish prisons. Legal and Criminological Psychology, 7, 131-140.

Liebling, A. (1992). Suicides in prison. London: Routledge.

Lipsey M. W., (1992). Juvenile delinquency treatment: A meta-analytic inquiry into the variability of effects. In Cook T., Cooper H., Cordray D. S., et al. (Eds.), Meta-Analysis for Explanation (pp. 83--126). New York: Russell Sage Foundation.

Lindquist, C. H. (2000). Social integration and mental well-being among jail inmates. Sociological Forum, 15, 431-455.

Listwan, S. J., Colvin, M., Hanley, D., \& Flannery, D. (2010). Victimization, social support,and psychological well-being: A study of recently released prisoners. Criminal Justice and Behavior, 37, 1140-1159.

Masten, A., \& Garmezy, N., Risk, Vulnerability and Protective Factors in Developmental Psychopathology. In F. Lahey \& A Kazdin (Eds.) Advances in Clinical Child Psychology (pp. 1-52). New York: Plenum (1985), at 3.

Miles, M. B. \& Huberman, M. (1994). Qualitative data analy-sis: An expanded sourcebook (2nd ed.). Thousand Oaks, CA: Sage.

Ministria e Drejtësisë. (Vjetari_statistikor 2010 Tiranë 2011)

Power, K., McElroy, J., \& Swanson, V. (1997). Coping abilities and prisoners: Perception of suicidal risk management. The Howard Journal, 36, 378-392.

Sykes, G. M. (1958). The pains of imprisonment. In G. M. Sykes (Ed.), The society of captives: A study of a maximum security prison (pp. 63-78). Princeton, NJ: Princeton University Press.

Toch, H. (1977) Living in Prison: The Ecology of Survival. New York: Free Press

Unicef.Sida 2007. Juvenile Delinquency in Albania .Tirana.Pages7.34-36

Van Herreveld, F.; Van Der Pligt, J.; Claassen, L. \& Van Dijk, W. W. (2007) 'Inmate Emotion Coping and Psychological and Physical Well-Being: The Use of Crying Over Spilled Milk'. Criminal Justice and Behavior 34 (5): 697-708

Wooldredge, J. D. (1999). Inmate experiences and psychological well-being. Criminal Justiceand Behavior, 26, 235-250.

Wright, K. N. (1993). Prison environment and behavioral outcomes. Journal of Offender Rehabilitation, 20, 93-113.

Zamble, E., \& Porporino, F. (1990). Coping, imprisonment, and rehabilitation: Some data and their implications. Criminal Justice and Behavior, 17, 53-70. 